\title{
Freehand Thoracic Pedicle Screw Placement: Review of Existing Strategies and a Step-by-Step Guide Using Uniform Landmarks for All Levels
}

\author{
Mauricio J. Avila $^{1}$, Ali A. Baaj ${ }^{2}$ \\ 1. Neurological Surgery, NewYork-Presbyterian/Weill Cornell Medical College 2. Neurological Surgery, \\ New York-Presbyterian/Weill Cornell Medical College
}

$\square$ Corresponding author: Mauricio J. Avila, avila.mao@gmail.com

Disclosures can be found in Additional Information at the end of the article

\section{Abstract}

Pedicle screw fixation in the thoracic spine presents certain challenges due to the critical regional neurovascular anatomy as well as the narrow pedicular corridor that typically exists. With increased awareness of the dangers of intraoperative radiation, the ability to place pedicle screws with anatomic landmarks alone is paramount. In this study, we reviewed the literature from 1990 to 2015 for studies that included freehand pedicle screw placement in the thoracic spine with special emphasis on entry points and the trajectories of the screws. We excluded studies that used fluoroscopy guidance, navigation techniques, cadaveric and biomechanical articles, case reports, and experimental studies on animals. The search retrieved 40 articles, and after careful selection, seven articles were analyzed. Over 8,000 screws were placed in the different studies. The mean accuracy for placement of the thoracic screws was $93.3 \%$. However, there is little consensus between studies in entry points, sagittal, and axial trajectories of the screws.

We complete this review by presenting our step-by-step technique for the placement of freehand pedicle screws in the thoracic spine.

Received 12/21/2015

Review began 01/28/2016

Review ended 02/08/2016

Published 02/19/2016

C) Copyright 2016

Avila et al. This is an open access article distributed under the terms of the Creative Commons Attribution License CC-BY 3.0., which permits unrestricted use, distribution, and reproduction in any medium, provided the original author and source are credited.
Categories: Neurosurgery, Orthopedics

Keywords: thoracic screws, pedicle screws, spinal fusion, thoracic vertebrae, spine deformity, spine surgery, spinal instrumentation, freehand technique

\section{Introduction And Background}

Pedicle screw and rod constructs have become widely accepted as the ideal option to provide stable spinal fixation [1-8].

Traditionally, freehand pedicle screw placement in the lumbar spine has had wide acceptance; however, pedicle screw placement in the thoracic spine has posed more challenges due to more challenging anatomy [9-10].

A variety of different techniques is currently used to aid the surgeon for accurate placement of pedicle screws in the thoracic spine. These techniques include intraoperative $\mathrm{C}$-arm fluoroscopy, intraoperative computer tomography (CT), and computer-assisted navigation [1116]. Although these adjunct technologies are playing a greater role in complex deformity 
surgery, drawbacks include radiation exposure to the patient and surgeon as well as high cost and prolonged operative time [13, 17-20].

Freehand pedicle screw placement in the thoracic spine is commonly performed by many surgeons and is both safe and effective [1-2, 17, 21-23]. Existing techniques, however, primarily rely on surgeon preferences and biases and may not provide easily reproducible parameters. Furthermore, most techniques describe varying entry points and trajectories depending on the thoracic spinal level or region [19, 24-25]. Due to the size of the thoracic pedicles and the proximity of vital structures in this region, the placement of freehand screws requires a high level of precision [10].

The goal of this study was to comprehensively review the existing published literature on freehand thoracic pedicle screw placement techniques, focusing on similarities and differences. Additionally, we present our step-by-step technique, which relies on a uniform entry point and sagittal trajectory for all levels.

\section{Review}

\section{Materials and Methods}

A review of the literature using the National Library of Medicine via the PubMed database was performed from 1990 to August 2015. Search words included: "freehand", "thoracic pedicle screw", and "technique". Only articles written in English were included. The title and abstract were screened and a first selection was done to include only the papers that discussed the specific techniques in the analysis. Specifically, we collected data on the number of patients, the number of inserted pedicle screws, and parameters of the surgical technique (entry point, axial, and sagittal trajectories). We excluded studies that involved fluoroscopy guidance, navigation techniques, cadaveric and biomechanical articles, case reports, and experimental studies on animals.

In order to encompass as many relevant studies as possible, we also performed a manual search of the references of selected articles.

\section{Results}

The search yielded a total of 40 published articles. Following the first selection by title and abstract, we identified seven [1-4, 23, 26-27] eligible studies that precisely detailed the technique of freehand thoracic pedicle screws placement. Overall, the seven studies represent a total of 1,602 patients with diverse pathologies and 8,586 screws in the thoracic spine. All the studies were retrospective case series; five out of seven represented a single surgeon experience, one study represented the experience of two surgeons [2], and one study represented the experience of eight different surgeons [3]. All the studies used postoperative CT scans to verify the positioning of the screws in the thoracic spine.

In Table 1, we present the details of the seven final articles included.

\begin{tabular}{|c|c|c|c|c|c|c|}
\hline \multirow[t]{2}{*}{$\begin{array}{l}\text { Authors \& } \\
\text { Year }\end{array}$} & Patients & $\begin{array}{l}\text { No. of } \\
\text { Screws }\end{array}$ & Spine Pathology & Entry Point & Axial Trajectory & $\begin{array}{l}\text { Sagittal } \\
\text { Trajectory }\end{array}$ \\
\hline & & & & $\begin{array}{l}\text { T1-T2: junction of the } \\
\text { transverse process and } \\
\text { lamina at the lateral pars } \\
\text { interarticularis; T3-T6: }\end{array}$ & & Proximal \\
\hline
\end{tabular}




\section{Cureus}

Kim, et al.

(2004)

Karapinar,

et al. 98

(2008)

Modi, et

al. (2009)

43

854

Modi, et

al. (2010)
Scoliosis $(273$

patients), Kyphosis (53

patients),

Fracture (45 patients),

Tumor (12 patients), Infection (4 patients),

Failed back surgery syndrome (7 patients)

Trauma (79 cases),

Scoliosis (12 cases),

Metastatic disease (3

cases),

Degenerative spine (2

cases)

Pott's disease (2

cases)

Scoliosis (Cobb angle

$\left(90^{\circ}\right.$ ): 22 idiopathic

and 21 neuromuscular

scoliosis patients

Severe scoliotic

deformities (Cobb

angle $>90^{\circ}$ ). Five

patients with

adolescent idiopathic

scoliosis and 21

patients with

neuromuscular

scoliosis

Degenerative/deformity

disease $(51.2 \%)$,

spondylolisthesis

(23.7\%), tumor

(22.7\%), trauma getting more lateral and

caudal; T7-T9: junction of

proximal edge of the

transverse process and

lamina just lateral to the

midportion of the base of

the superior articular

process; T11-T12: junction

of the transverse process

and lamina or just medial to

the lateral aspect of the pars

interarticularis.

T10, T11, and T12: The

junction of a vertical line

along the lateral pars

boundary and a transverse

line dividing the transverse

process in half.

"Medial orientation

of the awl's

trajectory

corresponded to a

line drawn from the

intended starting

point as described

to a point in the

anterior vertebral

body that allowed

for maximum screw

length and

triangulation

without a medial

breach of the

pedicle."

The junction of the outer third and inner two-thirds of the superior facet joint taken at the junction of the lateral and medial thirds of the facet joint after observing the whole facet joint margin.

The junction of the outer third and inner two-thirds of the superior facet joint taken at the junction of the lateral and medial thirds of the facet joint after observing the whole facet joint margin.

No guidelines for axial trajectories

No guidelines for axial trajectories

The center of a triangular bony confluence formed by the superior articular facet, the transverse process, and
Medio-lateral

trajectory is

performed to thoracic

region: more

lateral and

caudal. Apical

mid-thoracic

region: more

medial and

cephalad

No guidelines

for sagittal

trajectories

No guidelines for sagittal trajectories

No guidelines for sagittal trajectories

Parker, et 


\section{Cureus}

\begin{tabular}{|c|c|c|c|c|c|c|}
\hline al. (2011) & 964 & 3,443 & $\begin{array}{l}(11.3 \%), \text { infection } \\
(7.6 \%) \text {, and congenital } \\
(0.9 \%) . \text { Total of } \\
\text { patients for thoracic } \\
\text { and lumbar freehand } \\
\text { screws. }\end{array}$ & $\begin{array}{l}\text { the pars interarticularis. } \\
\text { Occurs medial to the lateral } \\
\text { margin of the superior } \\
\text { articular process. }\end{array}$ & $\begin{array}{l}\text { triangulate the } \\
\text { screw insertion } \\
\text { from lateral to } \\
\text { medial. }\end{array}$ & $\begin{array}{l}\text { superior } \\
\text { endplate of } \\
\text { the segment } \\
\text { of interest. }\end{array}$ \\
\hline $\begin{array}{l}\text { Rivkin, et } \\
\text { al. (2014) }\end{array}$ & 44 & 87 & $\begin{array}{l}\text { "Various pathologies } \\
\text { that needed } \\
\text { cervicothoracic fusion" } \\
\text { (non-described) }\end{array}$ & $\begin{array}{l}\text { T1 only: medial and superior } \\
\text { to the intersection of the } \\
\text { transverse process and pars } \\
\text { interarticularis. }\end{array}$ & $\begin{array}{l}\text { Medial-lateral } \\
\text { trajectory: line } \\
\text { drawn from the tip } \\
\text { of the spinous } \\
\text { process to the } \\
\text { contralateral entry } \\
\text { point. }\end{array}$ & $\begin{array}{l}\text { Cranial-caudal } \\
\text { trajectory: } \\
\text { perpendicular } \\
\text { to the long } \\
\text { axis of the } \mathrm{T} 1 \\
\text { lamina }\end{array}$ \\
\hline $\begin{array}{l}\text { Fennell, } \\
\text { et al. } \\
(2014)\end{array}$ & 33 & 219 & $\begin{array}{l}61 \% \text { Trauma, } 18 \% \\
\text { Tumor, } 12 \% \text { Infection, } \\
9 \% \text { Deformity }\end{array}$ & $\begin{array}{l}\text { For each level: } 3 \mathrm{~mm} \text { caudal } \\
\text { to the junction of the } \\
\text { transverse process and the } \\
\text { lateral margin of the } \\
\text { superior articulating } \\
\text { process }\end{array}$ & $\begin{array}{l}\text { Approximately } 30^{\circ} \\
\text { at } \mathrm{T} 1 \text { and } \mathrm{T} 2 \text {, and } \\
20^{\circ} \text { from } \mathrm{T} 3 \text { to } \mathrm{T} 12\end{array}$ & $\begin{array}{l}\text { Always } \\
\text { orthogonal to } \\
\text { the dorsal } \\
\text { curvature of } \\
\text { the spine at } \\
\text { corresponding } \\
\text { level. }\end{array}$ \\
\hline Total & 1,602 & 8,586 & & & & \\
\hline
\end{tabular}

\section{TABLE 1: Studies Describing Techniques for Freehand Placement of Thoracic Pedicle Screws}

Spine Pathologies

There were several pathologies involved in the placement of freehand thoracic screws: from moderate scoliosis (idiopathic and neuromuscular scoliosis) to severe scoliosis (Cobb angle > 90), to infection, Mal de Pott, trauma, tumors, metastasis, and congenital problems (Table 1) [1-4, 23, 26-27].

\section{Entry Points}

Various entry points have been proposed that are mainly based on the level of the thoracic spine.

Six of the seven studies focused on several thoracic levels. Only one study [4] focused on just one vertebral level, T1, with a modification of the technique described by Kim, et al. [2]. The details of the different entry points are available in Table 1.

\section{Trajectories}

Six studies evaluated axial and sagittal trajectories [1-4, 23, 28]. Nonetheless, the degree of explanation and details for these trajectories vary greatly. The majority of the reviewed studies mentioned directions of the screw rather than actual angles on the vertical or horizontal planes. 
The study by Fennell, et al. mentioned an axial trajectory of $30^{\circ}$ at the $\mathrm{T} 1$ and $\mathrm{T} 2$ vertebrae and $20^{\circ}$ from T3 to T12 [1]. Others studies compared the trajectory of the screw to the initial entry point line. Rivkin, et al. described a horizontal plane that was parallel to a line drawn from the tip of the spinous process to the contralateral entry point [4]. One study suggested the sagittal trajectory should rely on the superior endplate visualization of a corresponding thoracic vertebra [3].

\section{Accuracy of Freehand Thoracic Pedicle Screws}

The accuracy of thoracic pedicle screws placement was reported in all the studies. In general, pedicle screw accuracy was defined as "having the entire screw contained within the cortices of each respective pedicle" [3].

Mean accuracy rate for placement of pedicle screws in the studies was $93.34 \%$ (standard deviation of 3.54). The lowest reported accuracy was $87.4 \%$ [4] in screws only at T1 and the highest was $98.3 \%$ in their series of 964 patients [3]. Modi, et al. calculated the difference in accuracy for spine pathologies and found that the accuracy for patients with adolescent idiopathic scoliosis was $86.1 \%$, patients with cerebral palsy - 91.7\%, Duchenne's muscular dystrophy - 95.9\%, spinal muscular atrophy - 90.2\%, and polio - $84.4 \%$. The differences between diseases were not statistically significantly [26].

In studies with multiple surgeons, the accuracy for five surgeons was 93.8\% [2] and for eight surgeons was $98.3 \%$ [3].

\section{Breach of the Vertebral Bodies}

There was a consensus in all the studies of a "safe zone" from 2 to $4 \mathrm{~mm}$ for pedicle screw breach of the vertebral bodies. This safe zone allows the medial or lateral wall breach by the screw without clinical consequences for the patient [2, 23, 28]. Furthermore, the study by Kim, et al. defined a breach of $<2 \mathrm{~mm}$ as a "definite safe zone", a breach of 2 to $4 \mathrm{~mm}$ a "probable safe zone", and a breach of 4 to $8 \mathrm{~mm}$ as a "questionable safe zone" [2]. Furthermore, as shown by Karapinar, et al., the majority of the breaches are minor $(<2 \mathrm{~mm})$ in the thoracic spine [23].

Overall, a lateral breach was more common than a medial breach of the vertebral bodies. There was a range of $2.5 \%$ to $21.6 \%$ of the screws for lateral breach and $1.7 \%$ to $13.2 \%$ of the screws for medial breach, with the majority falling below $5 \%$ of the screws [1-4, 23, 26-27].

Four studies reported the most common location of the vertebral bodies' breaches. Parker, et al. [3] reported that T4 and T6 were the two most common sites for a breach with $4.1 \%$ and $4 \%$ of the screws at those levels, respectively. In the thoracolumbar junction, Karapinar, et al. [23] reported the breach rate of $16.4 \%$ at $\mathrm{T} 10,12.1 \%$ at $\mathrm{T} 11$, and $4.2 \%$ at $\mathrm{T} 12$. The two studies by Modi, et al. [26-27] reported that the middle thoracic spine (T5-T8) was the most common site for a breach in comparison with the upper and lower thoracic spine. Of the seven studies, only one reported the need for a revision surgery after a vertebral body breach in a patient with a T4 medial breach and osteomyelitis [3].

\section{Complications}

Overall, the complication rate after freehand pedicle screw placement in the thoracic spine was low. Parker, et al. reported $4.3 \%$ incidence of durotomies in their case series, however, this includes thoracic and lumbar freehand screw placement [3]. Kim, et al. reported no neurological or vascular complications in their series of 3,204 screws, which had up to 10 years follow- 
up [2].

\section{Discussion}

Thoracic pedicle screw fixation can be challenging due to the complex morphology of the thoracic vertebrae, which can lead to screw malposition with potential injury to adjacent structures [2, 6, 14, 29]. Although various intraoperative navigational techniques can be helpful to avoid misplacement of the screws, radiation exposure to both the patient and the surgeon is of great concern. To avoid harmful effects of radiation, freehand pedicle screw placement has become the preferred modality of fixation for various thoracic pathologies, such as trauma, degenerative spine disease, scoliosis, and tumors [1-3, 17, 29-30]. The diversity of spine pathologies where the freehand placement of thoracic screws has been successful is encouraging. Moreover, as navigation and assisted technologies become widely available, it is crucial that the spine surgeon still masters the anatomical basis of spine instrumentation and be comfortable with freehand techniques, especially to avoid the harmful effects of sustained radiation [31-34].

The accuracy of thoracic pedicle screw placement is high. In this review, Parker, et al. reported the highest rate of accurate placement (98.3\%) [3]. Their 1.7\% breach rate occurred in $9 \%$ of the total cohort of their patients. Nonetheless, only $0.8 \%$ required revision surgery for misplaced screws, which furthers add to the safety of a freehand technique. It is important to clarify that some studies reported different accuracy rates depending on whether or not they considered the "safe zone" to be an "accurate" screw. For example, Modi, et al. had an accuracy rate of $65.2 \%$ without including the "safe zone", but because a lot of the breaches were inside the "safe zone”, their reported final accuracy rate was 90.7\% [26]. Interestingly, they did not find any statistically significant difference between patient diagnosis and accuracy of the placement of pedicle screws. The latter adds support to the usefulness of a freehand technique in different pathologies.

In this review, we found a high range of reported lateral breaches of the vertebral bodies. The highest reported was by Modi, et al. of $21.6 \%$ and may be due to the fact that these screws were placed in patients with severe scoliosis where the anatomical landmarks may be more difficult to delineate [26]. Nonetheless, they did not report any neurological or vascular complications despite their high percentage of a breach. Furthermore, a $2.5 \%$ lateral breach in the series by Parker, et al. [3], the $4.1 \%$ by Fennell, et al. [1], the $5.8 \%$ by Karapinar, et al. [23], and the $6.2 \%$ by Kim, et al. [2] add support to the safety and feasibility of freehand thoracic screw placement in the thoracic spine. Parker, et al. were able to compare the breach rate of the thoracic and the lumbar freehand screws; the thoracic spine had a higher rate than the lumbar (2.5\% vs. $0.9 \%)$ [3]. This comes without a surprise as the pedicles in the lumbar spine are wider than the ones in the thoracic spine. The common connection between all the studies is that a lateral breach is far more prevalent than a medial breach. As Parker, et al. discussed, this may be because the surgeon will try to avoid the medial wall to prevent spinal cord damage as well as the higher thickness of the medial wall of the pedicle [3].

Kim, et al. suggested a "safe zone” for vertebral bodies' breach (medial and lateral) as follows: breach of $<2 \mathrm{~mm}$ as a "definite safe zone", a breach of 2 to $4 \mathrm{~mm}$ as a "probable safe zone", and a breach of 4 to $8 \mathrm{~mm}$ as a "questionable safe zone" [2]. Belmont, et al. expanded the "safe zone" for lateral breach up to $6 \mathrm{~mm}$ [28]. However, all the studies included in this review concurred that a breach of 2 to $4 \mathrm{~mm}$ is safe, and there is no need for repositioning the screws if the patient is asymptomatic; for this reason, we caution the reader against using the "expanded" safe zone as the majority of the studies limit the safe zone from 2 to $4 \mathrm{~mm}$. The study by Kim, et al. made the 4-8 mm limit as "questionable safe" rather than "safe" or "probably safe" [2]. We believe that the $4 \mathrm{~mm}$ limit is the most commonly used (and reported) upper limit for a breach. The existence of a "safe zone" for pedicle screw breach allows the spinal surgeons 


\section{Cureus}

to confidently use a freehand technique while allowing some room for improvement.

The complication rate in the reviewed studies was low. The majority of the studies reported no neurological or vascular complications following freehand placement of thoracic screws. The study by Kim, et al. provides the strongest evidence of the safety of this technique; they have the longest follow-up (10 years) without any neurological or vascular complication reported [2]. Moreover, even when comparing eight different surgeons, Parker, et al. [3] found an overall low complication rate in the over 3,000 screws placed. The latter suggests that the technique is still safe when used by different surgeons.

The results of this review highlight the fact that, while freehand thoracic screw placement techniques may be widely employed and are common, only a handful of published studies delineate the nuances of these techniques. Furthermore, the published studies highlight various starting points and/or trajectories for each level of the thoracic spine, making the adoption of the technique cumbersome to the spinal surgeon or trainee.

\section{Step-by-step technique}

We have recently proposed a technique that relies on less variable parameters and may be easier to teach [1]. We have had excellent early clinical experience with this at major training institutions and the clinical case series has previously been examined. Here, for the first time, we highlight a more detailed step-by-step guide to our technique:

Step 1

After the incision, dissection of the subcutaneous tissue and muscles the thoracic spine is exposed. The surgical exposure should include the superior articulating processes and transverse processes of the vertebrae. The inferior articulating process can be removed, if needed, for osteotomy but is not mandatory for screw placement alone (Figure 1).

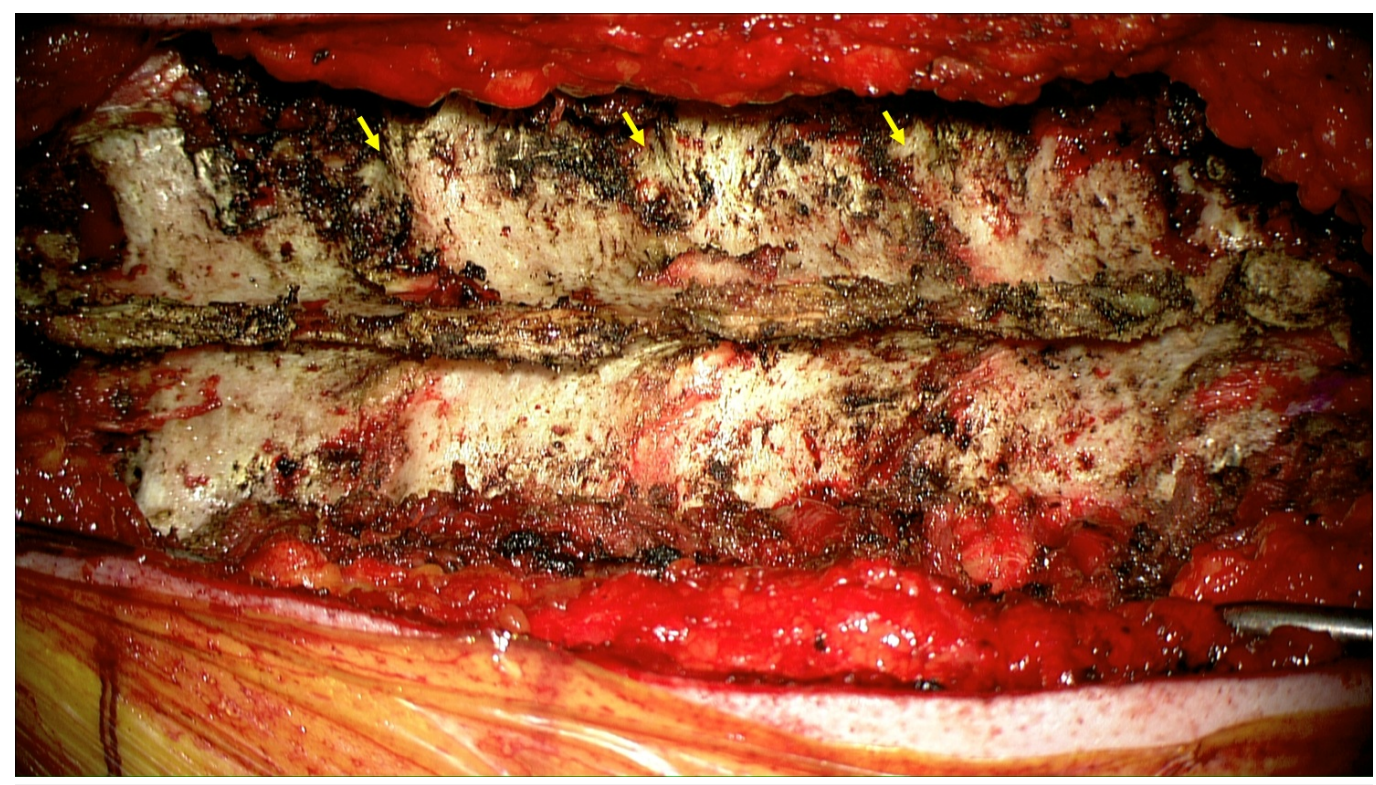

FIGURE 1: Exposure of thoracic spine showing the lateral edge of the superior articulating process and the transverse process. 


\section{Cureus}

Step 2

Then, we proceed with a decortication of the bone in the location of the entry point using highspeed electrical or pneumatic drill. For all levels in the thoracic spine, we use a uniform entry point, which is approximately $3 \mathrm{~mm}$ caudal to the junction of the lateral margin of the superior articulating process and the transverse process (Figure 2).

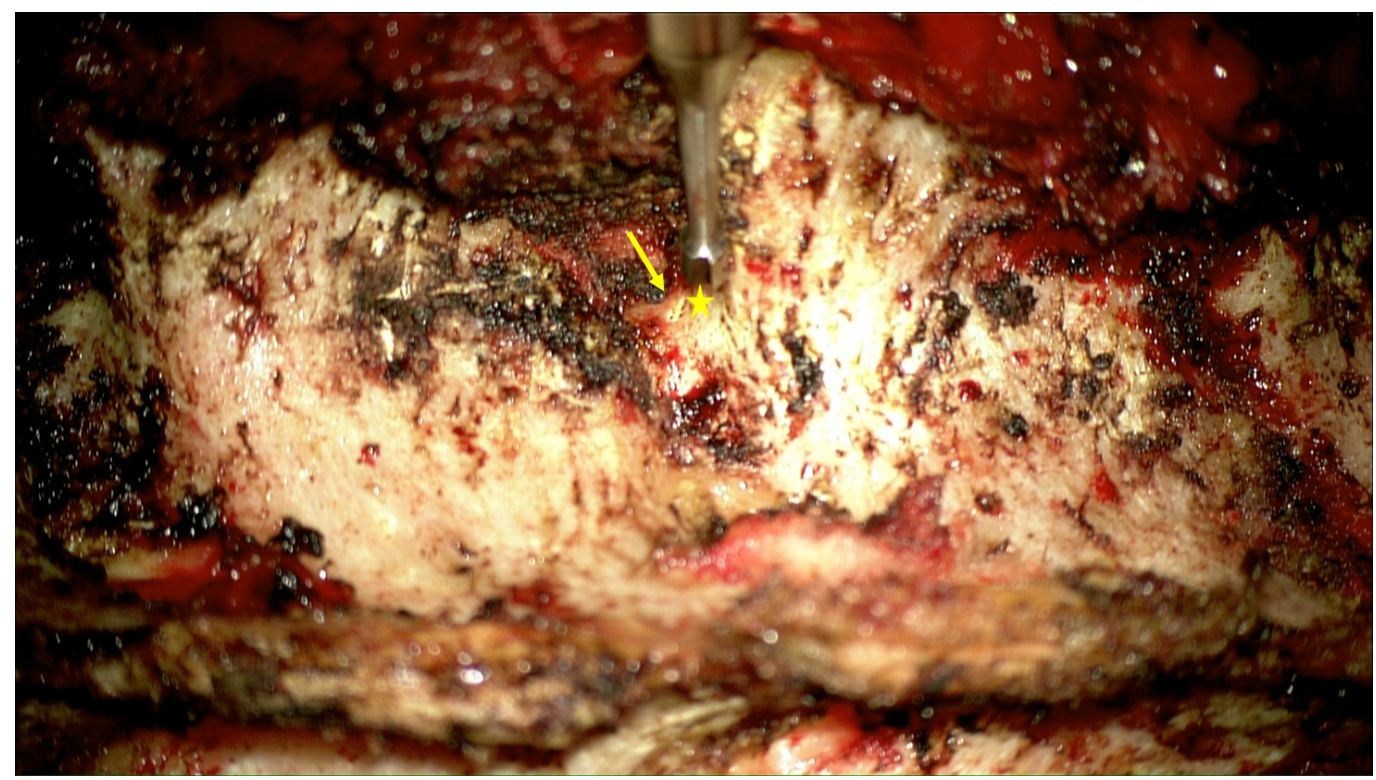

FIGURE 2: A high-speed drill is used to make an entry point. Note the entry point (star) is just caudal to the lateral edge of the superior articulating process-transverse junction (arrow).

Step 3

The pedicle is cannulated from the entry point and the gearshift probe is further advanced to the desired level based on a preoperative CT analysis, which also determines the length and diameter of the screw to be inserted. A straight gearshift is adequate, and the medial trajectory is approximately 30 degrees for $\mathrm{T} 1$ and $\mathrm{T} 2$, and 20 degrees for $\mathrm{T} 3$ through $\mathrm{T} 12$. The pedicle is cannulated in an orthogonal trajectory in relation to the dorsal spine (Figures 3-4). 


\section{Cureus}

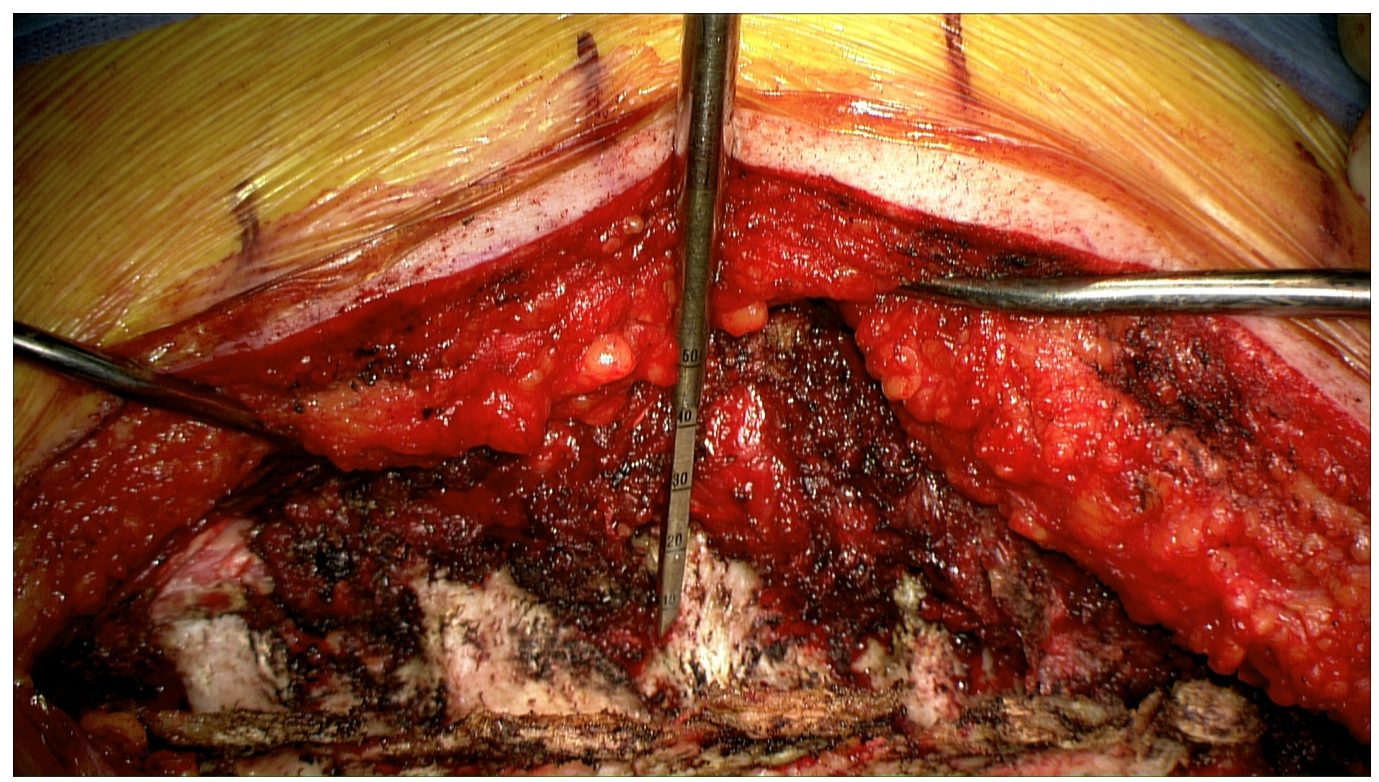

FIGURE 3: Cannulation of the pedicle using a straight narrow gearshift. 


\section{Cureus}

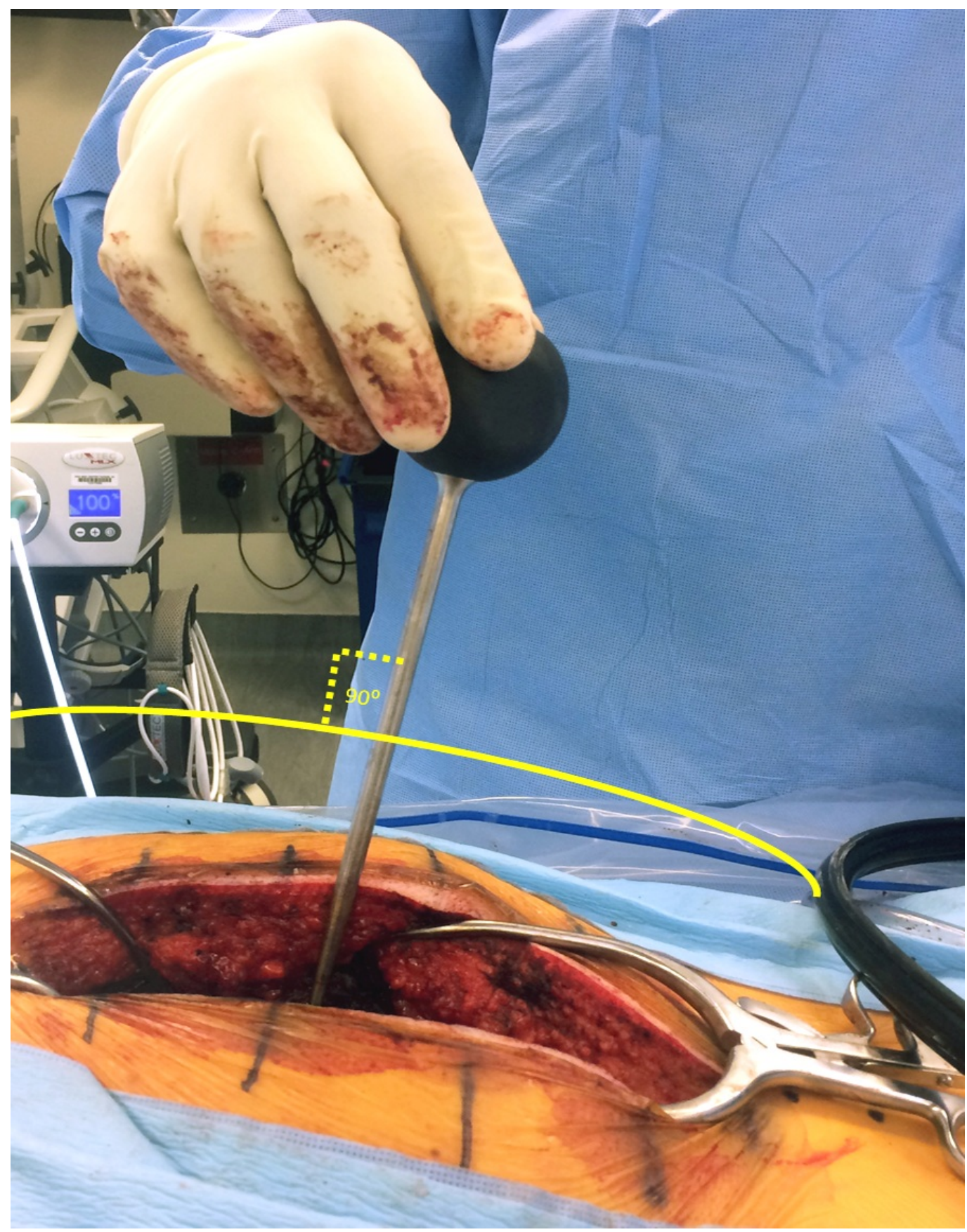

FIGURE 4: Cannulation is performed in an orthogonal fashion to the dorsal curvature of the spine to ensure a straight trajectory.

Step 4

The gearshift probe is removed, and a ball-tipped instrument is inserted to assess for any penetration (breach) of the bony wall in five directions: medially, laterally, superiorly, inferiorly, and anteriorly.

Step 5 


\section{Cureus}

With the use of a tap (which is $0.5-1 \mathrm{~mm}$ smaller than the intended pedicle screw), we undertap the pedicle tract. Then, the ball-tipped instrument is used to revise any possible vertebral body breach. After this, the pedicle screw can be inserted. Screw insertion can be performed using manual or powered drivers, our preference being the latter for ergonomic ease and better precision.

Step 6

The sagittal trajectory of the pedicle screw insertion should be maintained orthogonal to the curvature of the dorsal spine at each level.

Step 7

C-arm fluoroscopy with anterior-posterior (AP) and lateral views is used for initial localization and subsequent confirmation of appropriate screw insertion. Additional fluoroscopic images with pedicle markers in place are not necessary.

The uniform entry point that we identified is reproducible at each thoracic level as long as the cranial-caudal orthogonal cannulation trajectory is used as opposed to the earlier studies [2, 8 , 21 in which variable entry points were proposed with the tendency to be more lateral and caudal as one proceeds to the upper thoracic region and medial and cephalad as one proceeds distally (Figure 5). Low medial breach rates may be attributed to the importance of the more lateral entry point used in the proposed technique (Figures 6-7). The sagittal trajectory that we use is orthogonal to the curvature of the dorsal spine at the corresponding level. We feel that this is more practical than relating the trajectory to the plane of the transverse processes.

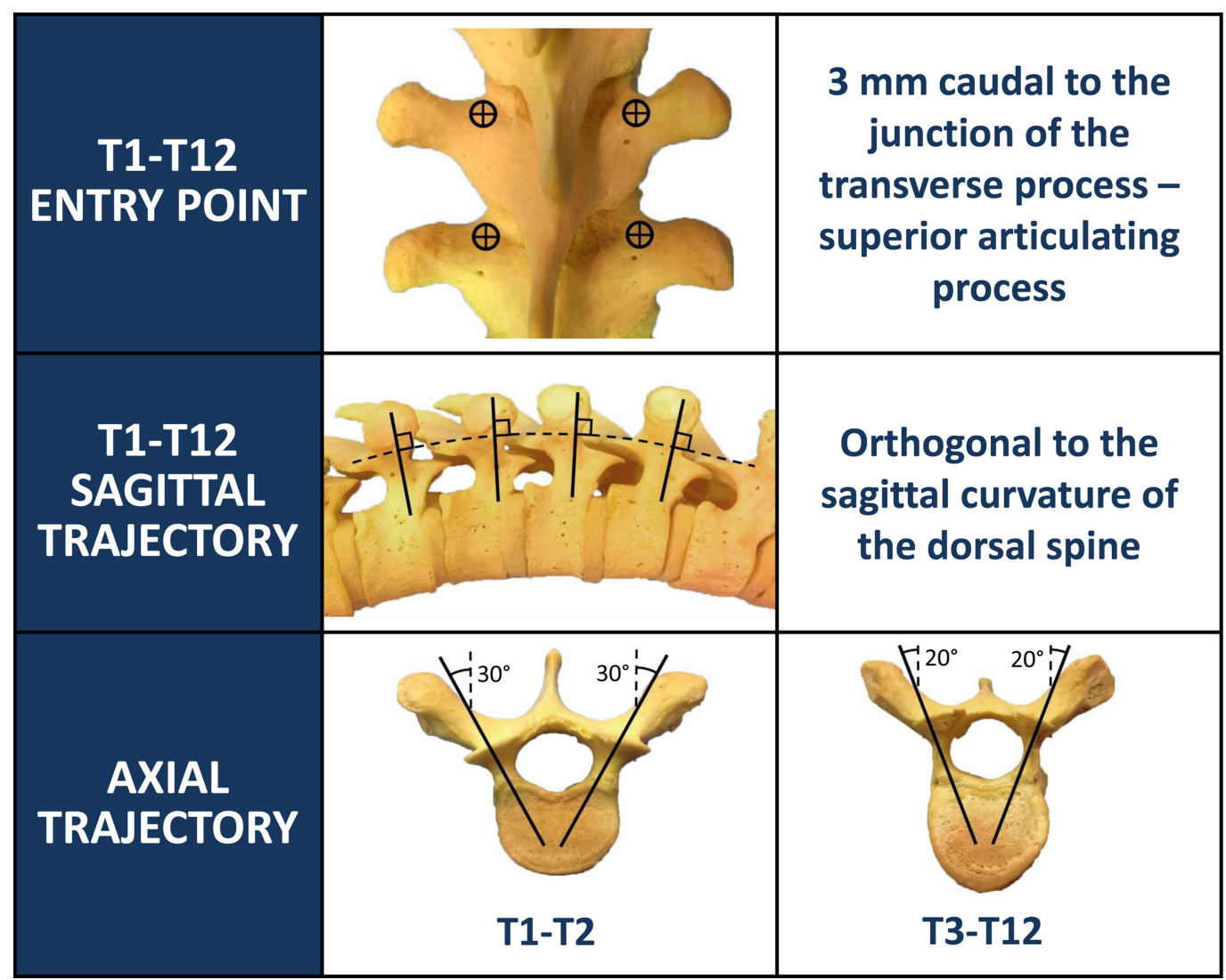

FIGURE 5: Entry point and trajectory chart for thoracic pedicle screw placement (Copyright: Ali A. Baaj, MD). 


\section{Cureus}

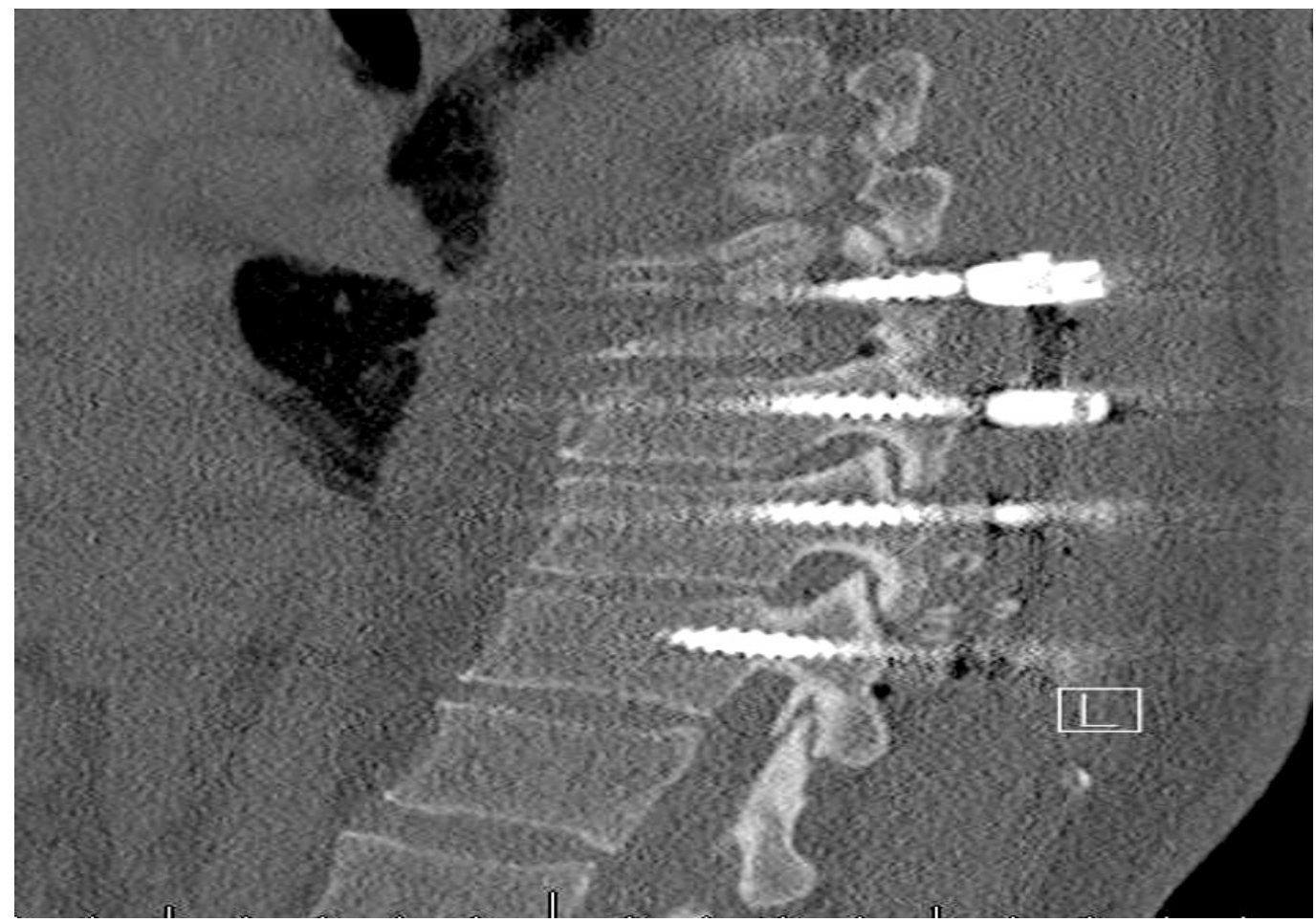

FIGURE 6: Parasagittal CT demonstrating the position of thoracic screws with proposed entry point and sagittal trajectory.

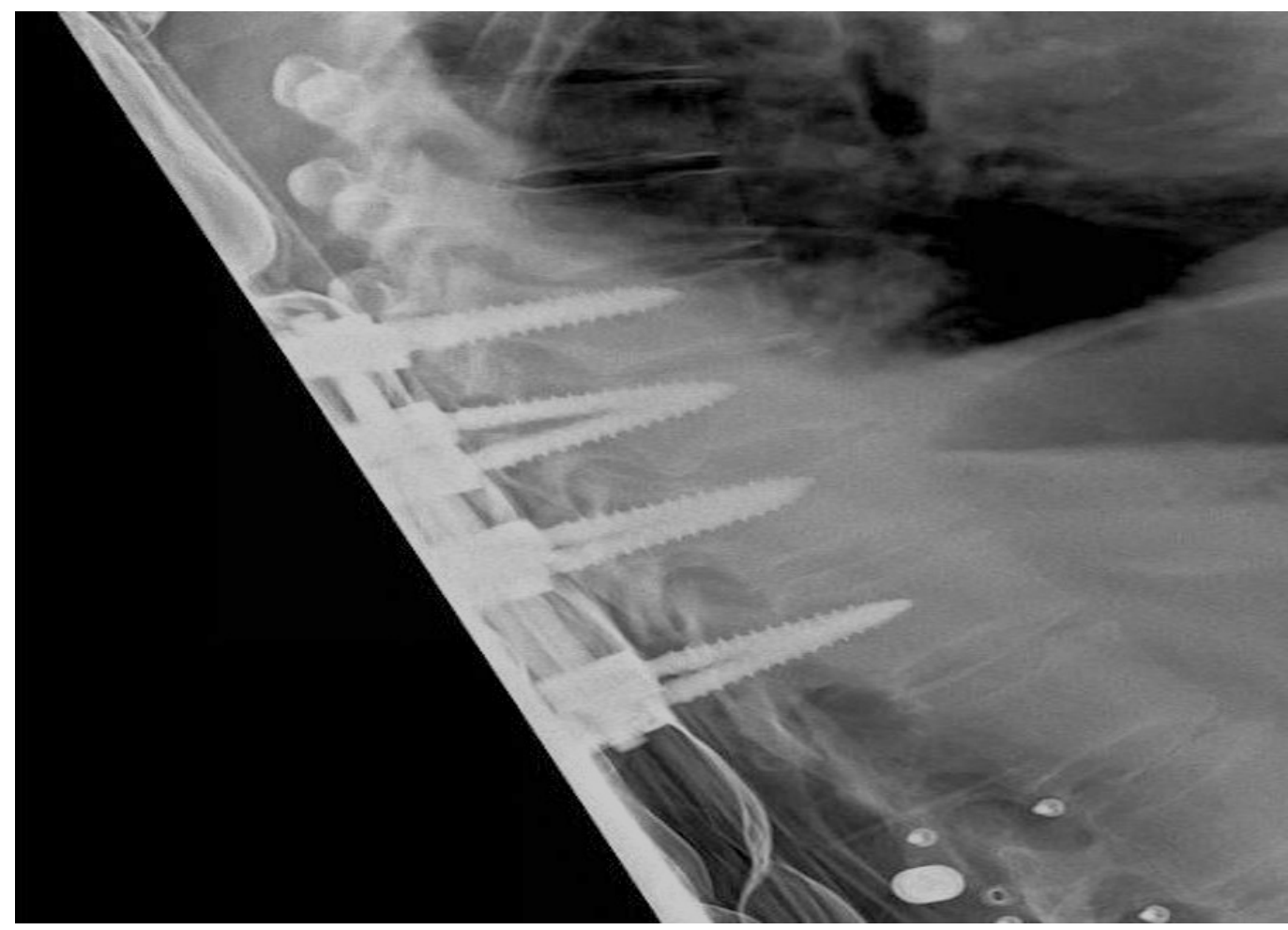




\section{Conclusions}

Freehand thoracic pedicle screw placement is safe and effective and may decrease operative times and radiation exposure. While many of the existing techniques are effective and generally accepted, we have proposed more uniform parameters that could make freehand thoracic pedicle screw placement easier to teach and learn.

\section{Additional Information}

\section{Disclosures}

Conflicts of interest: In compliance with the ICMJE uniform disclosure form, all authors declare the following: Payment/services info: All authors have declared that no financial support was received from any organization for the submitted work. Financial relationships: Ali A. Baaj declare(s) royalties from Thieme Publishers. Handbook of Spine Surgery. Other relationships: All authors have declared that there are no other relationships or activities that could appear to have influenced the submitted work.

\section{References}

1. Fennell VS, Palejwala S, Skoch J, Stidd DA, Baaj AA: Freehand thoracic pedicle screw technique using a uniform entry point and sagittal trajectory for all levels: preliminary clinical experience. J Neurosurg Spine. 2014, 21:778-84. 10.3171/2014.7.SPINE1489

2. Kim YJ, Lenke LG, Bridwell KH, Cho YS, Riew KD: Free hand pedicle screw placement in the thoracic spine: is it safe?. Spine (Phila Pa 1976). 2004, 29:333-42. 10.1097/01.BRS.0000109983.12113.9B

3. Parker SL, McGirt MJ, Farber SH, Amin AG, Rick AM, Suk I, Bydon A, Sciubba DM, Wolinsky JP, Gokaslan ZL, Witham TF: Accuracy of free-hand pedicle screws in the thoracic and lumbar spine: analysis of 6816 consecutive screws. Neurosurgery. 2011, 68:170-78. 10.1227/NEU.0b013e3181fdfaf4

4. $\quad$ Rivkin MA, Okun JF, Yocom SS: Novel free-hand T1 pedicle screw method: Review of 44 consecutive cases. J Neurosci Rural Pract. 2014, 5:349-54. 10.4103/0976-3147.139974

5. McCormack BM, Benzel EC, Adams MS, Baldwin NG, Rupp FW, Maher DJ: Anatomy of the thoracic pedicle. Neurosurgery. 1995, 37:303-308. 10.1227/00006123-199508000-00016

6. Hartl R, Theodore N, Dickman CA, Sonntag VKH: Technique of thoracic pedicle screw fixation for trauma. Operative Techniques in Neurosurgery. 2004, 7:22-30. 10.1053/j.otns.2004.04.005

7. Roy-Camille R, Saillant G, Berteaux D, Salgado V: Osteosynthesis of thoraco-lumbar spine fractures with metal plates screwed through the vertebral pedicles. Reconstr Surg Traumatol. 1976, 15:2-16.

8. Kim YJ, Lenke LG: Thoracic pedicle screw placement: free-hand technique . Neurol India. 2005, 53:512-19. 10.4103/0028-3886.22622

9. Motiei-Langroudi R, Sadeghian H: Assessment of pedicle screw placement accuracy in thoracolumbosacral spine using freehand technique aided by lateral fluoroscopy: results of postoperative computed tomography in 114 patients. Spine J. 2015, 15:700-704. 10.1016/j.spinee.2014.12.012

10. Gelalis ID, Paschos NK, Pakos EE, Politis AN, Arnaoutoglou CM, Karageorgos AC, Ploumis A, Xenakis TA: Accuracy of pedicle screw placement: a systematic review of prospective in vivo studies comparing free hand, fluoroscopy guidance and navigation techniques. Eur Spine J. 2012, $21: 247-55.10 .1007 / \mathrm{s} 00586-011-2011-3$

11. Carbone JJ, Tortolani PJ, Quartararo LG: Fluoroscopically assisted pedicle screw fixation for 
thoracic and thoracolumbar injuries: technique and short-term complications. Spine (Phila Pa 1976). 2003, 28:91-97. 10.1097/00007632-200301010-00021

12. Cui G, Wang Y, Kao TH, Zhang Y, Liu Z, Liu B, Li J, Zhang X, Zhu S, Lu N, Mao K, Wang Z, Zhang X, Yuan X, Dong T, Xiao S: Application of intraoperative computed tomography with or without navigation system in surgical correction of spinal deformity: a preliminary result of 59 consecutive human cases. Spine (Phila Pa 1976). 2012, 37:891-900.

10.1097/BRS.0b013e31823aff81

13. Youkilis AS, Quint DJ, McGillicuddy JE, Papadopoulos SM: Stereotactic navigation for placement of pedicle screws in the thoracic spine. Neurosurgery. 2001, 48:771-78. 10.1097/00006123-200104000-00015

14. Weinstein JN, Spratt KF, Spengler D, Brick C, Reid S: Spinal pedicle fixation: reliability and validity of roentgenogram-based assessment and surgical factors on successful screw placement. Spine (Phila Pa 1976). 1988, 13:1012-18.

15. Zhang C, Wang Z, Zhang C, Chen F, Zhang H, Yan X: Spine Bull's-Eye Robot guidewire placement with pedicle standard axis view for thoracic and lumbar pedicle screw fixation. J Spinal Disord Tech. 2012, 25:E191-198. 10.1097/BSD.0b013e31825ef937

16. Baaj AA, Beckman J, Smith DA: O-Arm-based image guidance in minimally invasive spine surgery: technical note. Clin Neurol Neurosurg. 2013, 115:342-45. 10.1016/j.clineuro.2012.05.007

17. Amiot LP, Lang K, Putzier M, Zippel H, Labelle H: Comparative results between conventional and computer-assisted pedicle screw installation in the thoracic, lumbar, and sacral spine. Spine (Phila Pa 1976). 2000, 25:606-14. 10.1097/00007632-200003010-00012

18. Assaker R, Reyns N, Vinchon M, Demondion X, Louis E: Transpedicular screw placement: image-guided versus lateral-view fluoroscopy: in vitro simulation. Spine (Phila Pa 1976). 2001, 26:2160-64. 10.1097/00007632-200110010-00024

19. Schwarzenbach O, Berlemann U, Jost B, Visarius H, Arm E, Langlotz F, Nolte LP, Ozdoba C: Accuracy of computer-assisted pedicle screw placement. An in vivo computed tomography analysis. Spine (Phila Pa 1976). 1997, 22:452-58. 10.1097/00007632-199702150-00020

20. Laine T, Lund T, Ylikoski M, Lohikoski J, Schlenzka D: Accuracy of pedicle screw insertion with and without computer assistance: a randomised controlled clinical study in 100 consecutive patients. Eur Spine J. 2000, 9:235-40. 10.1007/s005860000146

21. Hyun SJ, Kim YJ, Cheh G, Yoon SH, Rhim SC: Free hand pedicle screw placement in the thoracic spine without any radiographic guidance : Technical note, a cadaveric study. J Korean Neurosurg Soc. 2012, 51:66-70. 10.3340/jkns.2012.51.1.66

22. Rampersaud YR, Foley KT, Shen AC, Williams S, Solomito M: Radiation exposure to the spine surgeon during fluoroscopically assisted pedicle screw insertion. Spine (Phila Pa 1976). 2000, 25:2637-45. 10.1097/00007632-200010150-00016

23. Karapinar L, Erel N, Ozturk H, Altay T, Kaya A: Pedicle screw placement with a free hand technique in thoracolumbar spine: is it safe?. J Spinal Disord Tech. 2008, 21:63-67. 10.1097/BSD.0b013e3181453dc6

24. Kim YW, Lenke LG, Kim YJ, Bridwell KH, Kim YB, Watanabe K, Watanabe K: Free-hand pedicle screw placement during revision spinal surgery: analysis of 552 screws. Spine (Phila Pa 1976). 2008, 33:1141-48. 10.1097/BRS.0b013e31816f28a1

25. Lehman RA Jr, Polly DW Jr, Kuklo TR, Cunningham B, Kirk KL, Belmont PJ Jr: Straight-forward versus anatomic trajectory technique of thoracic pedicle screw fixation: a biomechanical analysis. Spine (Phila Pa 1976). 2003, 28:2058-65. 10.1097/01.brs.0000087743.57439.4f

26. Modi HN, Suh SW, Hong JY, Yang JH: Accuracy of thoracic pedicle screw using ideal pedicle entry point in severe scoliosis. Clin Orthop Relat Res. 2010, 468:1830-37. 10.1007/s11999010-1280-1

27. Modi H, Suh SW, Song HR, Yang JH: Accuracy of thoracic pedicle screw placement in scoliosis using the ideal pedicle entry point during the freehand technique. Int Orthop. 2009, 33:46975. 10.1007/s00264-008-0535-X

28. Belmont PJ Jr, Klemme WR, Dhawan A, Polly DW Jr: In vivo accuracy of thoracic pedicle screws. Spine (Phila Pa 1976). 2001, 26:2340-46. 10.1097/00007632-200111010-00010

29. Kosmopoulos V, Schizas C: Pedicle screw placement accuracy: a meta-analysis. Spine (Phila Pa 1976). 2007, 32:E111-20. 10.1097/01.brs.0000254048.79024.8b

30. Sarlak AY, Tosun B, Atmaca H, Sarisoy HT, Buluç L: Evaluation of thoracic pedicle screw placement in adolescent idiopathic scoliosis. Eur Spine J. 2009, 18:1892-97. 10.1007/s00586- 


\section{Cureus}

009-1065-y

31. Fard SA, Patel AS, Avila MJ, Sattarov KV, Walter CM, Skoch J, Baaj AA: Anatomic considerations of the anterior upper cervical spine during decompression and instrumentation: a cadaveric based study. J Clin Neurosci. 2015, 22:1810-15. 10.1016/j.jocn.2015.05.012

32. Alkadhim M, Zoccali C, Abbasifard S, Avila MJ, Patel AS, Sattarov K, Walter CM, Baaj AA: The surgical vascular anatomy of the minimally invasive lateral lumbar interbody approach: a cadaveric and radiographic analysis. Eur Spine J. 2015, 24:906-11. 10.1007/s00586-015-42675

33. Avila MJ, Skoch J, Fennell VS, Palejwala SK, Walter CM, Kim S, Baaj AA: Combined posterior hemiosteotomies and stabilization with lateral thoracotomy for en bloc resection of thoracic paraspinal primary bone tumors: technical note. J Neurosurg Spine. 2016, 24:223-27. 10.3171/2015.4.spine15107

34. Sattarov KV, Fard SA, Patel AS, Alkadhim M, Avila MJ, Walter CM, Baaj AA:

Peribrachiocephalic approaches to the anterior cervicothoracic spine . J Clin Neurosci. 2015, 22:1822-26. 10.1016/j.jocn.2015.05.028 